This is the accepted version of the following article:

JOURNAL OF ELECTROANALYTICAL CHEMISTRY 828 (2018) 86-90, published on-line on Sept. 20, 2018

DOI: 10.1016/j.jelechem.2018.09.028

\title{
Charge-transfer characteristics in carbon nanostructure/metal oxide photoelectrodes efficiently probed by hydrogen peroxide
}

Javier Hernández-Ferrer*, Alejandro Ansón-Casaos, Sandra Víctor-Román, Ana Santidrián, Ana M. Benito, Wolfgang K. Maser

Instituto de Carboquímica ICB-CSIC, Miguel Luesma Castán 4, E-50018 Zaragoza, Spain.

* Corresponding author. Tel.: +34 976 733977; fax: +34 976 733318; email: jhernandez@icb.csic.es

\begin{abstract}
The charge-transfer characteristics of nanostructured carbon $/ \mathrm{TiO}_{2}$ electrodes is studied by cyclic voltammetry under photoelectrochemical conditions exploiting the electrooxidation and electroreduction of $\mathrm{H}_{2} \mathrm{O}_{2}$ in an alkaline medium. Films of composites were prepared by physically mixing $\mathrm{TiO}_{2}$ with 5 wt.\% of either singlewalled carbon nanotubes (SWCNTs) or reduced graphene oxide (rGO). In addition, a layer-by-layer $\mathrm{rGO} / \mathrm{TiO}_{2}$ electrode was prepared. Under dark conditions, both mixed SWCNTs and rGO facilitate $\mathrm{H}_{2} \mathrm{O}_{2}$ reduction. Under light irradiation, the blank $\mathrm{TiO}_{2}$ electrode shows a cathodic photopotential, the $\mathrm{SWCNT} / \mathrm{TiO}_{2}$ an anodic photopotential, and the mixed $\mathrm{rGO} / \mathrm{TiO}_{2}$ an increased cathodic photopotential. This scenario unambiguously reveals a photoelectron acceptor behavior for SWCNTs and a photohole acceptor performance for rGO. The latter one also agrees with the photoactivity observed in the layer-by-layer electrode. Overall, the value of $\mathrm{H}_{2} \mathrm{O}_{2}$ redox reactions for
\end{abstract}


unraveling the electron-donor or electron-acceptor character of carbon nanostructures in $\mathrm{C} /$ metal oxide electrodes is demonstrated.

Keywords: titanium dioxide; carbon nanotube; graphene oxide; cyclic voltammetry; photoelectrochemistry

\section{Introduction}

Hydrogen peroxide $\left(\mathrm{H}_{2} \mathrm{O}_{2}\right)$ is often considered as a strong oxidizing agent with a very high standard potential. Specifically, under the conditions of this work $(\mathrm{pH}=13,0.1 \mathrm{M}$ $\mathrm{H}_{2} \mathrm{O}_{2}, 3$ ppm $\mathrm{O}_{2}$ ), the potentials for $\mathrm{H}_{2} \mathrm{O}_{2}$ reduction and oxidation are respectively:

$\mathrm{H}_{2} \mathrm{O}_{2}+2 e^{-} \rightleftharpoons 2 \mathrm{OH}^{-} ; \mathrm{E}^{0}=0.813 \mathrm{~V}($ vs. $\mathrm{Hg} / \mathrm{HgO}, 0.1 \mathrm{M} \mathrm{KOH})$

$\mathrm{O}_{2}+2 \mathrm{H}_{2} \mathrm{O}+2 e^{-} \rightleftharpoons \mathrm{H}_{2} \mathrm{O}_{2}+2 \mathrm{OH}^{-} ; \mathrm{E}^{0}=-0.372 \mathrm{~V}($ vs. $\mathrm{Hg} / \mathrm{HgO}, 0.1 \mathrm{M} \mathrm{KOH})$ (Eq. 2)

The potential of the reduction half-reaction is higher than the potential of the oxidation half-reaction, indicating that $\mathrm{H}_{2} \mathrm{O}_{2}$ is unstable by disproportionation. Moreover, $\mathrm{H}_{2} \mathrm{O}_{2}$ can act both as an electron[1] or a hole scavenger[2], depending on the considered electrochemical system. In fact, on $\mathrm{TiO}_{2}$ surfaces $\mathrm{H}_{2} \mathrm{O}_{2}$ has been previously employed as an electron acceptor to improve the oxidation of organic compounds[3-5], as well as to facilitate advanced sensing applications[6]. It has also been used as a complementary electron source to enhance the performance of photoanodes [7], which in turn, from a conceptual point of view, underlines its ability to accept photo-generated holes $[8,9]$

On the other hand, carbon nanomaterials, including carbon nanotubes and graphene in their different varieties, may work as electron or hole acceptors when they form composites with photoactive semiconducting materials. Carbon nanotubes usually behave as electron acceptors and improve the photoactivity of $\mathrm{TiO}_{2}$ at low nanotube contents[10]. For graphene, both electron[11] and hole acceptor[12, 13] behavior have 
been observed, depending on the characteristics of the material and the conditions of the experiments. Therefore, it is difficult to generalize the charge transfer behavior of graphene in complex systems with different configurations and kinetics. In this work we exploit for the first time the double redox reaction of $\mathrm{H}_{2} \mathrm{O}_{2}$ on carbon nanomaterial/semiconducting metal oxide comoposites and demonstrate its unique value for elucidating the charge transport characteristics of highly-purified singlewalled carbon nanotubes (SWCNTs) and reduced graphene oxide (rGO) in $\mathrm{TiO}_{2}$ composites. The energy levels of the $\mathrm{H}_{2} \mathrm{O}_{2}$ molecule and its relatively fast reaction kinetics appear to be highly suitable for understanding the pathway of photogenerated charges in these systems.

\section{Experimental methods}

\subsection{Materials and equipment}

Commercial $\mathrm{TiO}_{2}$ nanoparticles (Aeroxide P25, Evonik Degussa) were used in this work. SWCNTs (Small diameter $\mathrm{HiPCo}^{\mathrm{TM}}$ ) were purchased from NanoIntegris, Boisbriand, Canada. Graphite flakes were purchased from Aldrich (Ref. 332461). $\mathrm{NaOH}$ (reagent grade) was purchased from Sigma-Aldrich and extra-pure 30\% $\mathrm{H}_{2} \mathrm{O}_{2}$ from Fisher. FTO substrates $\left(70-100 \Omega / \mathrm{sq}, 80 \mathrm{~nm}\right.$ thickness, $2.5 \times 1 \mathrm{~cm}^{2}$ pieces) were purchased from SOLEMS ASAHI. A graphite rod (CYMIT Química) was used as the counter electrode. Photoelectrochemical measurements were performed in a threeelectrode cell with a quartz window, using an AUTOLAB PGSTAT302N. Illumination was carried out using a $150 \mathrm{~W}$ Xe arc lamp (LOT-Oriel GmbH, Germany). Scanning electron microscopy was carried out in a SEM EDX Hitachi S-3400 N microscope. 


\subsection{Aqueous inks of carbon nanomaterials}

The SWCNT powder material was ultrasonically dispersed in a surfactant at $1 \mathrm{mg} \cdot \mathrm{mL}^{-1}$, and purified by ultracentrifugation[14]. The SWCNT concentration in the supernatant dispersion was measured by optical absorption.

Graphene oxide (GO) was synthesized from graphite flakes by a modified Hummers method including an overnight reflux in $\mathrm{NaNO}_{3} / \mathrm{H}_{2} \mathrm{SO}_{4} / \mathrm{KMnO}_{4}$, cooling in $30 \% \mathrm{H}_{2} \mathrm{O}_{2}$,

filtration, resuspension in water at $0.5 \mathrm{mg} \cdot \mathrm{mL}^{-1}$, and exfoliation in an ultrasound bath[15]. The rGO ink was prepared by reaction of the GO dispersion with hydrazine under reflux conditions at $\mathrm{pH} \mathrm{9,} \mathrm{followed} \mathrm{by} \mathrm{dialysis,} \mathrm{in} \mathrm{order} \mathrm{to} \mathrm{remove} \mathrm{excess} \mathrm{reagent}$ and products.

\subsection{Electrode preparation}

Blank $\mathrm{TiO}_{2}$ films were prepared by spray-coating $1 \mathrm{~mL}$ of a $\mathrm{TiO}_{2}$ suspension in absolute ethanol $(2 \mathrm{mg} / \mathrm{mL})$ onto approximately $1 \mathrm{~cm}^{2}$ of the FTO substrate. The films were treated at $450^{\circ} \mathrm{C}$ for two hours in $\mathrm{N}_{2}$ atmosphere. Three different $\mathrm{C} / \mathrm{TiO}_{2}$ electrodes were prepared:

i) A SWCNT/ $/ \mathrm{TiO}_{2}$ electrode, which contained approximately 5 wt.\% SWCNTs, by mixing the SWCNT supernatant with the $\mathrm{TiO}_{2}$ dispersion. The films were washed in water to remove traces of remaining surfactant.

ii) An $\mathrm{rGO} / \mathrm{TiO}_{2}$ electrode, which contained $5 \mathrm{wt} . \%$ in $\mathrm{rGO}$, by mixing the rGO ink with the $\mathrm{TiO}_{2}$ dispersion.

These two electrodes were also treated at $450{ }^{\circ} \mathrm{C}$ in $\mathrm{N}_{2}$ atmosphere. 
iii) A layer-by-layer ( $\mathrm{L}-) \mathrm{rGO} / \mathrm{TiO}_{2}$ electrode. $\mathrm{GO}$ dispersion was spray-coated on a blank $\mathrm{TiO}_{2}$ electrode. The average thickness of the GO layer was $20 \mathrm{~nm}$ as probed by profilometry (Bruker DektakXT Stylus). Finally, the GO layer was electrochemically reduced applying four potentiodynamic cycles between -0.040 and $-1.440 \mathrm{~V}(\mathrm{Hg} / \mathrm{HgO}$ $0.1 \mathrm{M} \mathrm{KOH})$.

\subsection{Electrochemical measurements}

Voltammograms were performed using $\mathrm{N}_{2}$-purged $0.1 \mathrm{M} \mathrm{NaOH}$ as the supporting electrolyte, a $\mathrm{Hg} / \mathrm{HgO}(0.1 \mathrm{M} \mathrm{KOH})$ reference electrode and a graphite counter electrode. The scan rate was $20 \mathrm{mV} / \mathrm{s}$, and the second cycle is presented here in all the cases. The photoactivity was tested in $0.1 \mathrm{M} \mathrm{H}_{2} \mathrm{O}_{2}$. Photopotential was calculated according to:

$\mathrm{V}_{\mathrm{ph}}=\mathrm{E}_{\text {light }}-\mathrm{E}_{\text {dark }}$

where $E_{\text {light }}$ and $E_{\text {dark }}$ are the zero current voltage with and without illumination respectively. The maximum photocurrent density $\mathrm{j}_{\mathrm{ph}}$ is calculated at both the anodic and cathodic branches of the voltammograms, as the largest difference of the current density between light and dark conditions:

$\mathrm{j}_{\mathrm{ph}}=\max \left(\mathrm{j}_{\text {light }}-\mathrm{j}_{\text {dark }}\right)$

\section{Results and discussion}

\subsection{SEM micrographs.}

SEM images show a homogeneous $\mathrm{TiO}_{2}$ layer with larger aggregates on its surface (figure 1A). For the $\mathrm{SWCNT} / \mathrm{TiO}_{2}$ electrode (figure $1 \mathrm{~B}$ ), a homogeneous surface is observed. The absence of aggregates of $\mathrm{TiO}_{2}$ and SWCNTs is indicative of a rather 
uniformly composed material. The $\mathrm{rGO} / \mathrm{TiO} 2$ electrode (figure $1 \mathrm{C}$ ) is characterized by individual rGO sheets, homogeneously dispersed throughout the $\mathrm{TiO}_{2}$ matrix. Contrarily, the L-rGO/TiO2 electrode (figure 1D) looks very similar to the $\mathrm{TiO}_{2}$ one, but "blurred" by the rGO layer, which appears as a uniform and homogeneous top-layer.

\subsection{Dark voltammetry in $\mathrm{NaOH}$}

The electrodes were characterized by cyclic voltammetry, in dark conditions, in $0.1 \mathrm{M}$ $\mathrm{NaOH}$ (Figure 1). Blank $\mathrm{TiO}_{2}$ exhibits the typical electrochemical behavior that can be found in the literature[16]. The main characteristic of the $\mathrm{SWCNT} / \mathrm{TiO}_{2}$ electrode is the presence of large cathodic/anodic peaks in the $\mathrm{TiO}_{2}$ bandgap region that can be associated to charge accumulation in the proximity of SWCNTs, due to the availability of new electronic states in the proximities of the $\mathrm{TiO}_{2}$ conduction band[10]. In contrast, the $\mathrm{rGO} / \mathrm{TiO}_{2}$ voltammogram resembles the blank $\mathrm{TiO}_{2}$ electrode. The layer-by-layer L$\mathrm{rGO} / \mathrm{TiO}_{2}$ electrode experiences an increase in the electrode capacitive character and in the faradaic cathodic current for water reduction $(\sim-1.4 \mathrm{~V})$, which can be attributed to an improvement in the electrical conductivity of the system[17], due to the presence of the top rGO layer.

\subsection{Voltammetry in $\mathrm{H}_{2} \mathrm{O}_{2}$}

CVs were carried out at a high concentration of $\mathrm{H}_{2} \mathrm{O}_{2}$, both under dark conditions and xenon lamp illumination (Figure 2). Forward and backward scans of each voltammogram are identical, not revealing any hysteresis loop. The curves (Figure 2) show negative and positive branches, according to the consumption of $\mathrm{H}_{2} \mathrm{O}_{2}$ by reduction to $\mathrm{OH}^{-}$(Eq. 1) and oxidation to $\mathrm{O}_{2}$ (Eq. 2) respectively. For blank $\mathrm{TiO}_{2}$ in dark conditions (Figure 3A, 3B), the zero-current potential is located at $-0.224 \mathrm{~V}$, which 
is near the oxidation potential of hydrogen peroxide. Therefore, according to the classical mixed potential theory[18], $\mathrm{H}_{2} \mathrm{O}_{2}$ electro-oxidation is faster than $\mathrm{H}_{2} \mathrm{O}_{2}$ electroreduction. However, under illumination the electrode develops an activity in the cathodic branch (Figure 2B). Even though $\mathrm{H}_{2} \mathrm{O}_{2}$ might undergo photochemical reactions in liquid phase[19, 20], previous studies have shown that the main source of photoactivity refers to the reaction of $\mathrm{H}_{2} \mathrm{O}_{2}$ on $\mathrm{TiO}_{2}$ surfaces, rather than to homogeneous photocomposition processes of $\mathrm{H}_{2} \mathrm{O}_{2}[3,4]$.

The presence of SWCNTs changes substantially the response of $\mathrm{TiO}_{2}$. Under dark conditions (Figure 3B), anodic current decreases, cathodic current increases, and zerocurrent potential is $44 \mathrm{mV}$ more positive than for $\mathrm{TiO}_{2}$ alone. Therefore, the SWCNT/TiO 2 electrode shows an improved behavior for $\mathrm{H}_{2} \mathrm{O}_{2}$ electro-reduction. Apparently, SWCNTs might provide additional electronic states that help the electron transfer to the $\mathrm{H}_{2} \mathrm{O}_{2}$ molecule in the dark. Under illumination (Figure 2B), the $\mathrm{SWCNT} / \mathrm{TiO}_{2}$ electrode develops a clear photoanodic activity.

For the $\mathrm{rGO} / \mathrm{TiO}_{2}$ electrode in dark conditions (figure 3B), there is a decrease in the anodic value of the current, and an increase in the cathodic branch, compared to $\mathrm{TiO}_{2}$ alone. The trend is analogous to that observed for the $\mathrm{SWCNT} / \mathrm{TiO}_{2}$ electrode, and the different currents are most likely associated to variations in the electronic states provided by the carbon nanomaterials. Zero-current potential for the $\mathrm{rGO} / \mathrm{TiO}_{2}$ electrodes does not change significantly compared to the $\mathrm{TiO}_{2}$ electrode. Under illumination, $\mathrm{rGO} / \mathrm{TiO}_{2}$ remains as photocathode (Figure $3 \mathrm{C}$ ), contrary to the behavior of the $\mathrm{SWCNT} / \mathrm{TiO}_{2}$ electrode.

In the $\mathrm{L}-\mathrm{rGO} / \mathrm{TiO}_{2}$ electrode, the continuous rGO layer blocks the direct contact between the $\mathrm{TiO}_{2}$ and the electrolyte, thus entirely changing the electrode-electrolyte interphase. The $\mathrm{H}_{2} \mathrm{O}_{2}$ electro-oxidation is favored in the dark (Figure 3B), while $\mathrm{H}_{2} \mathrm{O}_{2}$ 
electro-reduction is hindered with respect to the composite $\mathrm{rGO} / \mathrm{TiO}_{2}$ electrode. Under illumination, the photoanodic process is slightly favored (Figure 3C).

In summary, the electrochemical behavior in $\mathrm{H}_{2} \mathrm{O}_{2}$ under dark conditions depends on the electrode configuration (composite or layered), rather than on the type of carbon nanostructure itself (SWCNT or rGO). Both carbon nanomaterials perform similarly in the dark, while behaving totally different under light irradiation. This suggests that electronic levels from the valence band of the carbon nanomaterials are involved in charge transfer under dark conditions, while the conduction band levels of SWCNTs may play a role when electrons are excited to the $\mathrm{TiO}_{2}$ conduction band. The effects of light irradiation are further discussed in the following paragraphs.

\subsection{Photopotential and photocurrent density in $\mathrm{H}_{2} \mathrm{O}_{2}$}

$\mathrm{V}_{\mathrm{ph}}$ and $\mathrm{j}_{\mathrm{ph}}$ for all the electrodes are plotted in Figure 3D and 3E. Positive $V_{\mathrm{ph}}$ and negative $j_{\text {ph }}$ indicate the ability of the electrode to work as a photocathode $\left(\mathrm{H}_{2} \mathrm{O}_{2}\right.$ photoreduction), while negative $\mathrm{V}_{\mathrm{ph}}$ and positive $\mathrm{j}_{\mathrm{ph}}$ are associated to a photoanode behavior $\left(\mathrm{H}_{2} \mathrm{O}_{2}\right.$ photooxidation). Blank $\mathrm{TiO}_{2}$ shows a negative (cathodic) photocurrent $\left(-93 \mu \mathrm{A} \cdot \mathrm{cm}^{-2}\right)$, together with a positive $\mathrm{V}_{\mathrm{ph}}(+37 \mathrm{mV})$ indicating that $\mathrm{H}_{2} \mathrm{O}_{2}$ is able to extract photogenerated electrons from the $\mathrm{TiO}_{2}$ conduction band.

The photoresponse of the electrode changes considerably after the addition of SWCNTs. Unlike blank $\mathrm{TiO}_{2}$, the $\mathrm{SWCNT} / \mathrm{TiO}_{2}$ electrode behaves as a photoanode, yielding a high positive $\mathrm{j}_{\mathrm{ph}}\left(+79 \mu \mathrm{A} \cdot \mathrm{cm}^{-2}\right)$ and negative $\mathrm{V}_{\mathrm{ph}}(-217 \mathrm{mV})$. Therefore, $\mathrm{H}_{2} \mathrm{O}_{2}$ is able to react rapidly with the photogenerated holes on $\mathrm{TiO}_{2}$ surfaces, while the photoelectrons from the $\mathrm{TiO}_{2}$ conduction band are transferred to the SWCNT trap states, thus hindering recombination. This observation agrees with the presence of 
electronic levels near the $\mathrm{TiO}_{2}$ accumulation region (conduction band) in the reference voltammogram (Fig. 2). In previous experiments with water and methanol [10], even though SWCNTs showed photoelectron accepting properties, they did act as recombination centers. It seems that recombination rate was faster than water and methanol photoooxidation, and photocurrent was completely blocked in the $\mathrm{SWCNT} / \mathrm{TiO}_{2}$ electrode. However, a high oxidation photocurrent for $\mathrm{H}_{2} \mathrm{O}_{2}$ seems to confirm the role of SWCNTs as electron acceptors, further implying that $\mathrm{H}_{2} \mathrm{O}_{2}$ oxidation is faster than recombination.

The $\mathrm{V}_{\mathrm{ph}}$ for mixed $\mathrm{rGO} / \mathrm{TiO}_{2}$ increases compared to $\mathrm{TiO}_{2}(+45$ and $+37 \mathrm{mV}$, respectively), indicating an improvement in charge separation. The positive photopotential is associated with the accumulation of positive charges in the electrode. The rGO additive thus improves the amount of accumulated photoholes and reveals an hole-acceptor behavior. Also, cathodic photocurrent is higher for rGO in the potential range between -0.15 and $-0.35 \mathrm{~V}$ (figure $3 \mathrm{~B}$ ). However, maximum cathodic $\mathrm{j}_{\mathrm{ph}}$ for $\mathrm{rGO} / \mathrm{TiO}_{2}$ is lower than for $\mathrm{TiO}_{2}\left(-48\right.$ and $-64 \mu \mathrm{A} \cdot \mathrm{cm}^{-2}$, respectively). The photoelectrons are not easily transferred to the electrolyte, indicating that rGO eventually may act as recombination center.

In the $\mathrm{L}-\mathrm{rGO} / \mathrm{TiO}_{2}$ electrode the sign of $\mathrm{V}_{\mathrm{ph}}$ changes. The rGO layer hinders the direct contact between $\mathrm{TiO}_{2}$ and the electrolyte, blocking the photoelectron transfer from $\mathrm{TiO}_{2}$ to $\mathrm{H}_{2} \mathrm{O}_{2}$. The cathodic photocurrent nearly disappears due to the blocking effect, while an anodic photocurrent appears, reaching $+16 \mu \mathrm{A} \cdot \mathrm{cm}^{-2}$. Therefore, the rGO material acts as an acceptor of photoholes and allows the transport of holes from the electrode to the solution. The $\mathrm{L}-\mathrm{rGO} / \mathrm{TiO}_{2}$ response is compatible with the hole acceptor behavior of rGO previously observed in the mixed $\mathrm{rGO} / \mathrm{TiO}_{2}$ electrode. 
Figure 3 clearly shows that $\mathrm{H}_{2} \mathrm{O}_{2}$ can be used to unravel charge transfer mechanisms of the different carbon nanostructures and confirm that SWCNTs act as electron acceptors while rGO acts as a hole acceptor from photoexcited $\mathrm{TiO}_{2}$. Furthermore, the photoactivity of rGO in a layer-by-layer configuration qualitatively agrees with the one observed in the mixed composite electrode. The exterior layer of carbon nanomaterials hinders the $\mathrm{TiO}_{2}$ contact with the solution, and may even change the cathodic/anodic character of the electrode.

\section{Conclusions}

Photoelectrochemical study of the double $\mathrm{H}_{2} \mathrm{O}_{2}$ redox reaction can be employed for the analysis of the charge transfer behavior of carbon nanostructures in $\mathrm{C} / \mathrm{TiO}_{2}$ composites. This strategy is particularly useful since $\mathrm{H}_{2} \mathrm{O}_{2}$ photooxidation is faster than electron/hole recombination processes. The results, particularly photopotential measurements, reveal a photoelectron acceptor behavior in the case of SWCNT-based electrodes under light irradiation and a photohole acceptor behavior for rGO-based electrodes. Hole accepting properties of rGO also agree with the behavior of a layer-bylayer $\mathrm{rGO} / \mathrm{TiO}_{2}$ electrode.

\section{Acknowledgements}

The authors thank Dr. B. Villacampa (University of Zaragoza) for the profilometer analysis, MSc. O. Sanahuja for GO preparation, and Eng. C. Rubio Muñoz for the $\mathrm{SWCNT} / \mathrm{TiO}_{2}$ electrode preparation. This work has been funded by MINECO and European Regional Development Fund (ENE 2016-79282-C5-1-R), the Government of Aragon (T03-17R), and European Commission (H2020-MSCA-ITN-2014-ETN 642742 “Enabling Excellence"). 


\section{References}

[1] T. Hirakawa, Y. Nosaka, Properties of $\mathrm{O}_{2} \bullet-$ and $\mathrm{OH} \bullet$ Formed in $\mathrm{TiO}_{2}$ Aqueous Suspensions by Photocatalytic Reaction and the Influence of $\mathrm{H}_{2} \mathrm{O}_{2}$ and Some Ions, Langmuir, 18 (2002) 3247-3254.

[2] H. Dotan, K. Sivula, M. Grätzel, A. Rothschild, S.C. Warren, Probing the photoelectrochemical properties of hematite $\left(\alpha-\mathrm{Fe}_{2} \mathrm{O}_{3}\right)$ electrodes using hydrogen peroxide as a hole scavenger, Energy Environ. Sci., 4 (2011) 958-964.

[3] X. Li, C. Chen, J. Zhao, Mechanism of Photodecomposition of $\mathrm{H}_{2} \mathrm{O}_{2}$ on $\mathrm{TiO}_{2}$ Surfaces under Visible Light Irradiation, Langmuir, 17 (2001) 4118-4122.

[4] H. Zúñiga-Benítez, G.A. Peñuela, Solar lab and pilot scale photo-oxidation of ethylparaben using $\mathrm{H}_{2} \mathrm{O}_{2}$ and $\mathrm{TiO}_{2}$ in aqueous solutions, J. Photochem. and Photobiol. A: Chem., 337 (2017) 62-70.

[5] Y. Du, J. Rabani, The Measure of $\mathrm{TiO}_{2}$ Photocatalytic Efficiency and the Comparison of Different Photocatalytic Titania, J. Phys. Chem. B, 107 (2003) 1197011978.

[6] X. Xi, J. Li, H. Wang, Q. Zhao, H. Li, Non-enzymatic photoelectrochemical sensing of hydrogen peroxide using hierarchically structured zinc oxide hybridized with graphite-like carbon nitride, Microchim. Acta, 182 (2015) 1273-1279.

[7] K.D. Malviya, D. Klotz, H. Dotan, D. Shlenkevich, A. Tsyganok, H. Mor, A. Rothschild, Influence of Ti Doping Levels on the Photoelectrochemical Properties of Thin-Film Hematite ( $\left.\alpha-\mathrm{Fe}_{2} \mathrm{O}_{3}\right)$ Photoanodes, J. Phys. Chem. C, 121 (2017) 4206-4213. [8] A. Akita, T. Masuda, K. Fujiwara, M. Fujishima, H. Tada, One-Compartment Hydrogen Peroxide-Photofuel Cell Using $\mathrm{TiO}_{2}$ Photoanode and Prussian Blue Cathode, J. Electrochem. Soc., 165 (2018) F300-F304. 
[9] K. Fujiwara, A. Akita, S. Kawano, M. Fujishima, H. Tada, Hydrogen peroxidephotofuel cell using TiO2 photoanode, Electrochem. Commun., 84 (2017) 71-74. [10] A. Ansón-Casaos, J. Hernández-Ferrer, C. Rubio-Muñoz, A. Santidrian, M.T. Martínez, A.M. Benito, W.K. Maser, Electron Trap States and Photopotential of Nanocrystalline Titanium Dioxide Electrodes Filled with Single-Walled Carbon Nanotubes, ChemElectroChem, 4 (2017) 2300-2307.

[11] G. Xie, K. Zhang, B. Guo, Q. Liu, L. Fang, J.R. Gong, Graphene-Based Materials for Hydrogen Generation from Light-Driven Water Splitting, Adv. Mater., 25 (2013) $3820-3839$.

[12] A. Du, Y.H. Ng, N.J. Bell, Z. Zhu, R. Amal, S.C. Smith, Hybrid graphene/titania nanocomposite: Interface charge transfer, hole doping, and sensitization for visible light response, J. Phys. Chem. Lett., 2 (2011) 894-899.

[13] L. Ferrighi, G. Fazio, C.D. Valentin, Charge Carriers Separation at the Graphene/(101) Anatase TiO2 Interface, Adv. Mater. Interf., 3 (2016).

[14] A. Ansón-Casaos, J.M. González-Domínguez, I. Lafragüeta, J.A. Carrodeguas, M.T. Martínez, Optical absorption response of chemically modified single-walled carbon nanotubes upon ultracentrifugation in various dispersants, Carbon, 66 (2014) $105-118$

[15] J.D. Nunez, A.M. Benito, S. Rouziere, P. Launois, R. Arenal, P.M. Ajayan, W.K. Maser, Graphene oxide-carbon nanotube hybrid assemblies: cooperatively strengthened $\mathrm{OH} \cdots \mathrm{O}=\mathrm{C}$ hydrogen bonds and the removal of chemisorbed water, Chem. Sci., 8 (2017) 4987-4995.

[16] T. Berger, D. Monllor-Satoca, M. Jankulovska, T. Lana-Villarreal, R. Gómez, The electrochemistry of nanostructured titanium dioxide electrodes, ChemPhysChem, 13 (2012) 2824-2875. 
[17] F. Fabregat-Santiago, I. Mora-Seró, G. Garcia-Belmonte, J. Bisquert, Cyclic voltammetry studies of nanoporous semiconductors. Capacitive and reactive properties of nanocrystalline TiO2 electrodes in aqueous electrolyte, J. Phys. Chem. B, 107 (2003) $758-768$

[18] Mixed Potential Theory, in: N. Perez (Ed.) Electrochemistry and Corrosion Science, Springer US, Boston, MA, 2004, pp. 155-166.

[19] J.P. Hunt, H. Taube, The Photochemical Decomposition of Hydrogen Peroxide. Quantum Yields, Tracer and Fractionation Effects, J. Am. Chem. Soc., 74 (1952) 59996002.

[20] B.H.J. Bielski, A.O. Allen, Mechanism of the disproportionation of superoxide radicals, J. Phys. Chem., 81 (1977) 1048-1050.

\section{Figure captions}

Figure 1. SEM micrographs of the electrodes.

Figure 2. Cyclic voltammograms in dark conditions, $0.1 \mathrm{M} \mathrm{NaOH}$.

Figure 3. (A-C) Cyclic voltammograms in $0.1 \mathrm{M} \mathrm{H}_{2} \mathrm{O}_{2}$. (D, E) Photopotential and maximal photocurrent obtained by cyclic voltammetry in $0.1 \mathrm{M} \mathrm{H}_{2} \mathrm{O}_{2}$. 


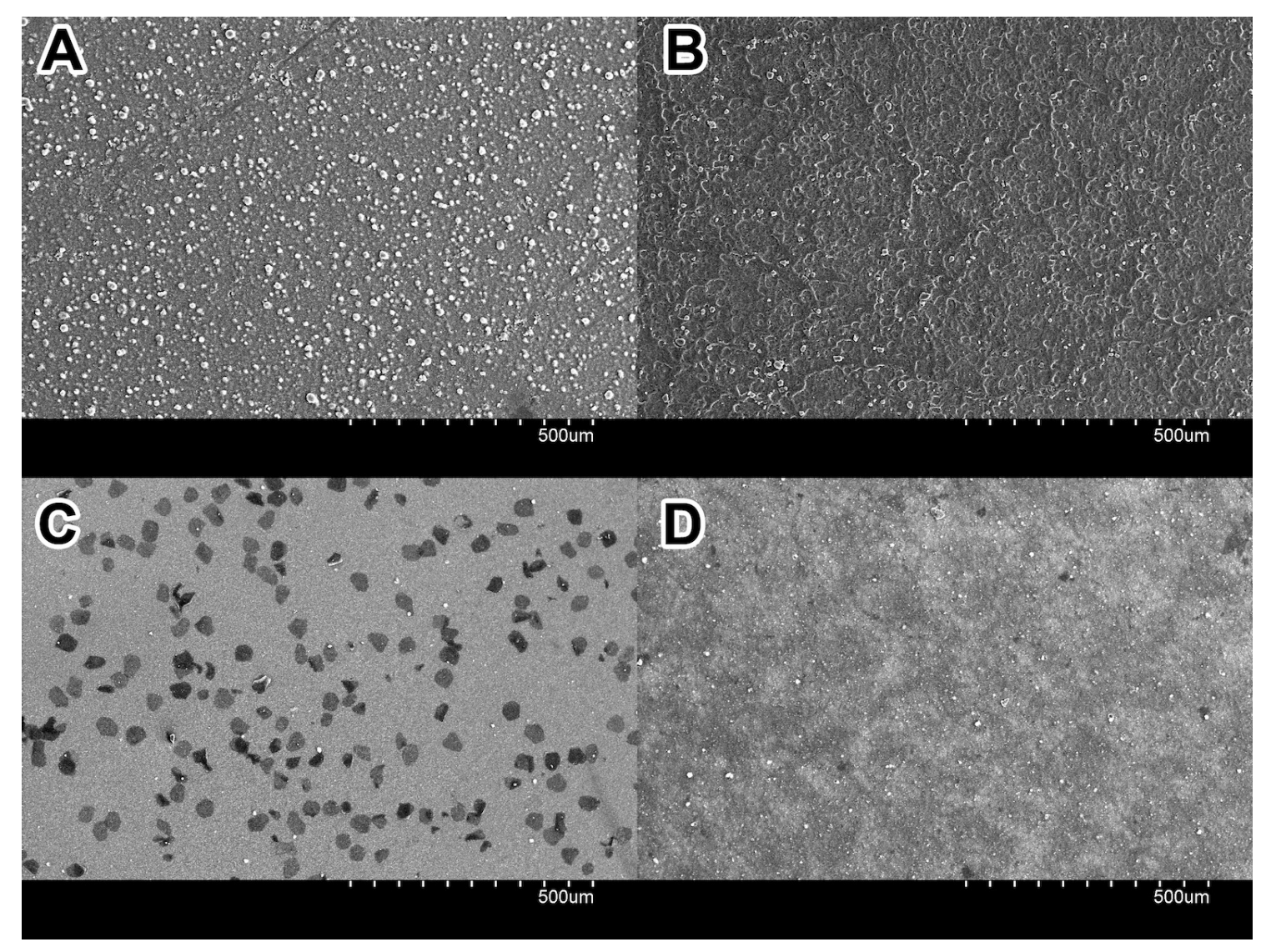

Figure 1 


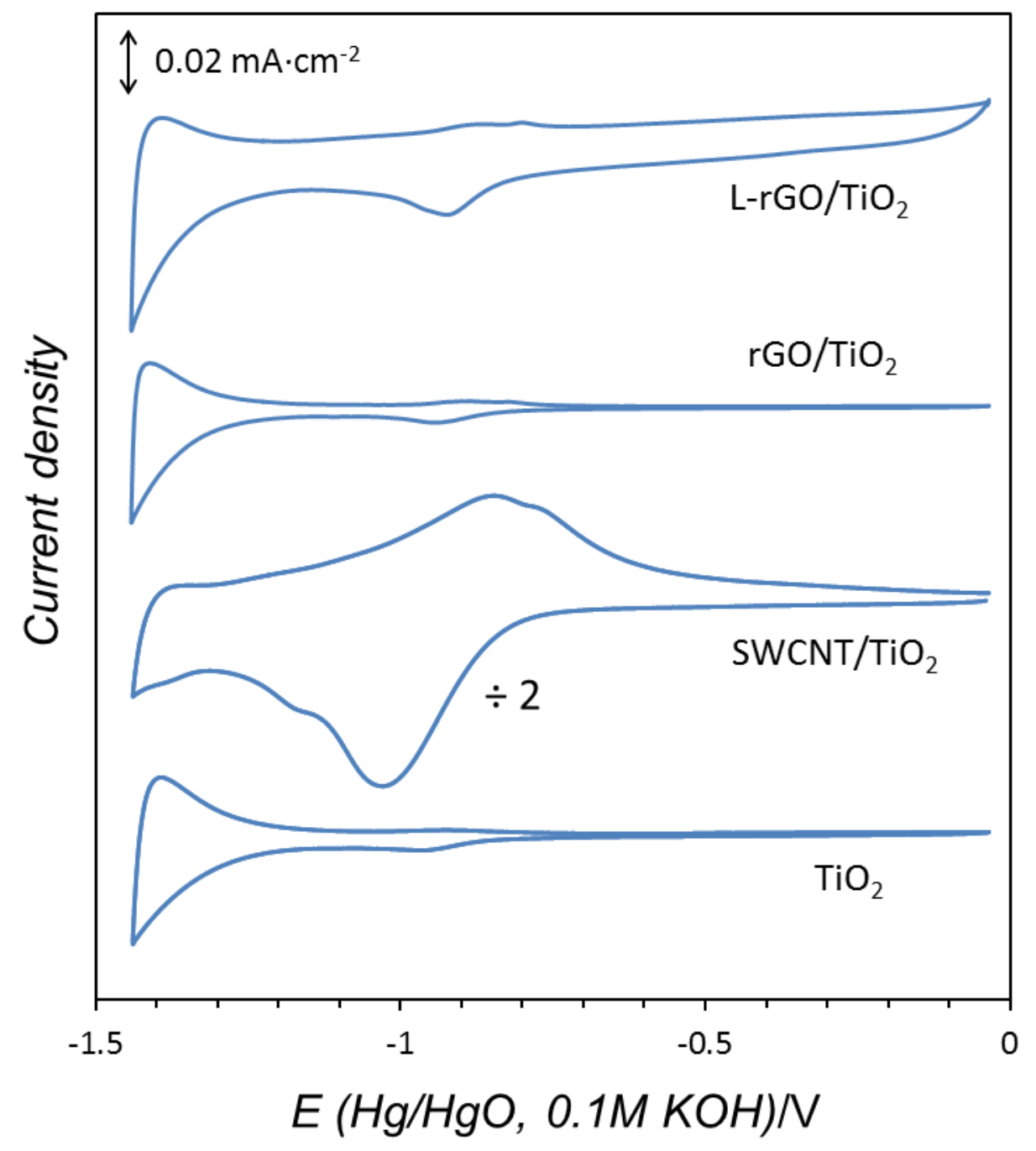

Figure 2 

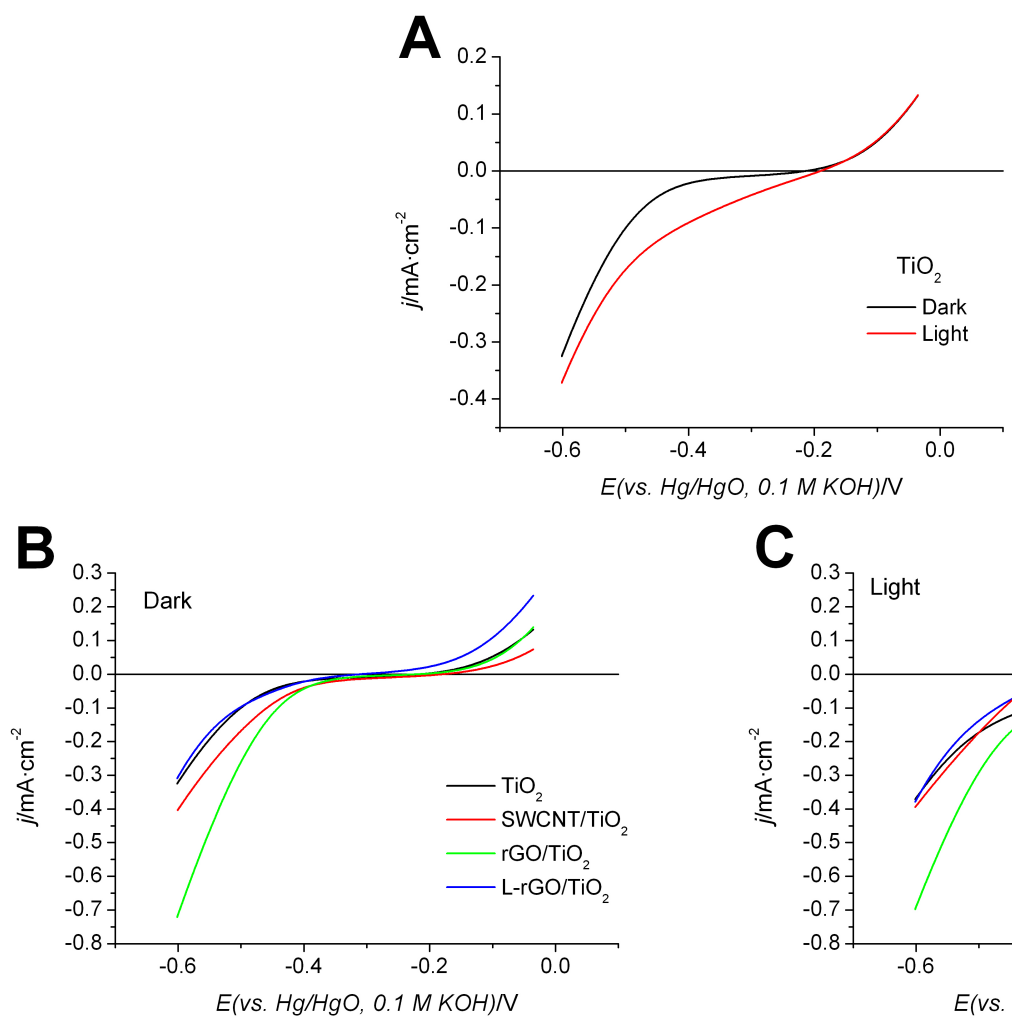

C
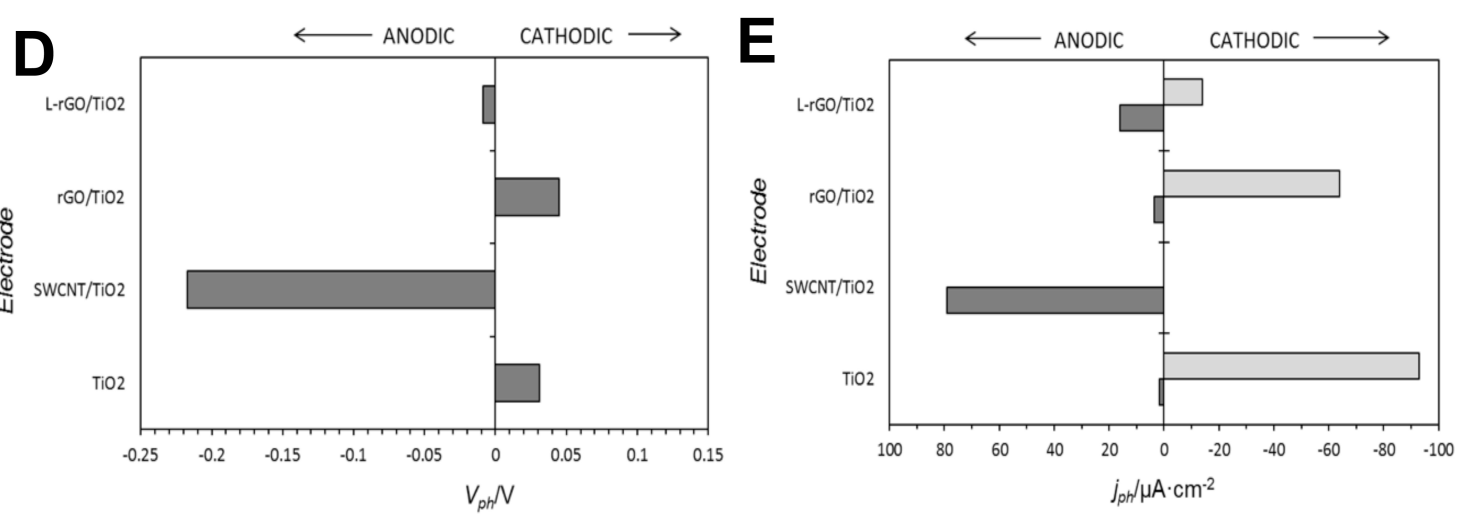

Figure 3 